\title{
Sex Pheromone of the Female Large Cabbage-heart Caterpillar, Crocidolomia binotalis Zeller (Lepidoptera: Pyralidae)
}

\author{
Kenji Usui, Masaaki Kurihara, Kyoichi UchiUmi, \\ Jun-ichi Fukami and Sadahiro Tatsuki* \\ Laboratory of Insect Toxicology, The Institute of Physical and Chemical Research, \\ Wako-shi, Saitama 351-01, Japan \\ * Institute of Agriculture and Forestry, University of Tsukuba, \\ Sakura-mura, Ibaraki 305, Japan
}

Received March 2, 1987

\begin{abstract}
Sex pheromone components of the female Crocidolomia binotalis, an insect pest of cabbages in Indonesia, were identified from the ovipositor tip extract of virgin females by analyzing with chromatographic fractionation and capillary GC/MS. In an EAG response and attractivity test with a wind tunnel system, a mixture of synthetic compounds, (Z)-9-tetradecenyl acetate (Z-9TDA) and (Z)-11-hexadecenyl acetate (Z-11-HDA), in the ratio of $1: 7-1: 60$ and an amount of $1 \sim 50 \mathrm{ng}$ on a filter paper, showed strong activities comparable to the activity of the ovipositor tip extract, which contained the two compounds at a ratio of $c$. 1:10 (Z-9-TDA:Z-11-HDA). The mixture of these two compounds might be the sex pheromone of $C$. binotalis.
\end{abstract}

The large cabbage-heart caterpillar, Crocidolomia binotalis Zeller (Lepidoptera: Pyralidae), is a notorious pest of vegetables in the tropical and subtropical areas. Larvae of this insect seriously injure cabbages by eating into their hearts. Therfore, control of this pest by pesticides is rather difficult. Application of the pheromone is expected to control this pest as well as forecasting its occurrence.

Pheromone components of many lepidopteran insect pests which attack cabbages have so far been identified. Some of these are (Z)-7-dodecenyl acetate (Z-7-DDA) and dodecyl acetate for Trichoplusia $n i^{1)} ;(Z, E)$ 9,11-tetradecadienyl acetate and $(Z, E)-9,12$ tetradecadienyl acetate for Spodoptera litura ${ }^{2}$; (Z)-11-hexadecenyl acetate (Z-11-HDA) and (Z)-11-hexadecenal for Plutella xylostella ${ }^{3)}$; Z11-HDA for Mamestra brassicae ${ }^{4)}$; Z-5-DDA and Z-7-DDA for Agrotis fucosa ${ }^{5)}$; Z-7-DDA and ( $Z$ )-9-tetradecenyl acetate (Z-9-TDA) for Agrotis ipsilon ${ }^{6}$; and $(E, E)-11,13$-hexadecadienal for Hellula undalis. ${ }^{7)}$

This paper reports components of the female $C$. binotalis pheromone.

\section{MATERIALS AND METHODS}

Insect. Crocidolomia binotalis Zeller originally imported from Indonesia was successively reared on an artificial diet in the Insectron of our laboratory under a $12 \mathrm{hr}$ light $-12 \mathrm{hr}$ dark photocondition at $25 \pm 1^{\circ} \mathrm{C}$ as described previously. ${ }^{8)}$ The sexes were separated at the pupal stage and held in screened cages with a dilute honey solution under an allday light condition.

Pheromone extraction. Ovipositor tips of 1- to 5-day-old virgin female moths were excised and soaked in a small volume of $n$-hexane (ca. $10 \mu \mathrm{l} /$ tip) at $8-9 \mathrm{hr}$ after lights-out and extracted for $0.5 \sim 1 \mathrm{hr}$. The extract was stored at $-20^{\circ} \mathrm{C}$ until used.

GC for analysis and fractionation. GC analysis and fractionation of the crude extract were carried out with $5 \%$ OV-101 on $60 \sim 80$ mesh Chromosorb W (AW-DMCS) $(3 \mathrm{~mm} \times 2 \mathrm{~m})$ or with $5 \%$ PEG-20M on $100 \sim 120$ mesh Chromosorb W (AW-DMCS) $(3 \mathrm{~mm} \times 2 \mathrm{~m}$, Applied Science Laboratories Inc.) using a Shimadzu GC 5A equipped with FID at a constant oven temperature of 166 or $176^{\circ} \mathrm{C}$, respectively. The fractions were collected in glass tubes $(2.5 \mathrm{~mm} \times 35 \mathrm{~cm})$ and extracted with a small volume of hexane. The crude extract was also fractionated with column chromatography of Florisil ( $5 \sim 6 \mathrm{~mm}$ i.d. $\times$ $7 \sim 8 \mathrm{~cm}$ high, $60 \sim 80 \mathrm{mesh}$, Floridin Co.) containing 7\% $\mathrm{H}_{2} \mathrm{O}$, eluting with $6 \mathrm{ml}$ each of hexane (1st), and with $5 \%$ 
(2nd), $15 \%$ (3rd) and 50\% (4th) ether in hexane.

Functional group test. The crude extract was hydrolyzed with $5 \% \mathrm{KOH}$ in methanol for several hours at room temperature and extracted with hexane. The hexane extract of the hydrolyzate was then acetylated with a drop of acetyl chloride. The hydrolyzate and the reacetylated crude extracts were checked for their attracting activity against male moths in the wind tunnel.

Wind tunnel test. The attracting activities of the crude extract, GC and Florisil fractions, and synthetic compounds to males of the moth were tested in a wind tunnel $(45 \times 45 \times 200 \mathrm{~cm})$ in dark conditions (below 0.1 lux).$^{9)}$ When the males were active to the samples, 1- to 4-day-old male moths (kept under all-day light condition) were used after $6 \mathrm{hr}$ from light-out. A small strip of filter paper, which had been treated with the crude extract, the fractions or synthetic compounds, was placed on a sheet of light-colored cardboard $(20 \times 30 \mathrm{~cm})$ located at a $20 \mathrm{~cm}$ height near the upwind end of the tunnel. For one or two test series, about 60 preconditioned male moths were introduced into the tunnel from the downwind end. Their behavioral response to each pheromone source, the number of the males and approximate distance from the pheromone source that each male reached were observed for $1 \sim 2 \mathrm{~min}$. An interval of about $10 \mathrm{~min}$ between each test was set without the pheromone sources.

EAG activity. The EAG responses of male antennae of the moth were recorded according to the manner described previously. ${ }^{10)}$ Each antenna was puffed with $1 \mathrm{ml}$ of air through a glass cartridge $(2.5 \mathrm{~mm}$ i.d. $\times 15 \mathrm{~cm})$, whose inside wall had been treated with the extract, the fraction or synthetic compounds.

GC/MS with a capillary column. GC/MS was measured with a Shimadzu GCMS-QP1000 equipped with a fused silica capillary column of chemically bonded PEG-20M $(0.25 \mathrm{~mm} \times 50 \mathrm{~m}$, Gasukuro Kogyo Co. $)$ and a solvent-cut injection system. EI (electron impact ionization) mode at $70 \mathrm{eV}$ and $240^{\circ} \mathrm{C}$, and TIC (total ion chromatography) were selected. The retention times $\left(t_{R}\right)$ and mass spectra were compared with those of the standard synthetic compounds.

Chemicals. Synthetic Z-9-TDA, Z-11-TDA and Z-11HDA were kindly provided from Shin-etsu Chemical Industries Co., Ltd., and their purities were estimated to be over $99 \%$ by GC analysis. Serial tetradecenyl acetates and hexadecenyl acetates were kind gifts from Dr. T. Ando of Tokyo University of Agriculture and Technology, and others were of the highest purity commercially available. Solvents (ether, methanol and $n$ hexane) were distilled before use.

\section{RESULTS AND DISCUSSION}

The male attracting activity of the crude ovipositor tip extract of virgin female C. $b i$ notalis was examined in the wind tunnel. The step (grade) of the activity by which the moths were attracted to the pheromone source was scored as follows: $1(-)$, no activity; $2( \pm)$, upwind orientation flight to $50 \sim 30 \mathrm{~cm}$ from the source; $3(+)$, reduction of speed followed by hovering, backing up and/or zigzag flight to about $15 \mathrm{~cm}$ from the source, near the downwind end of the cardboard; $4(++)$, slowapproach flight directly to the source without landing; and $5(++)$, contacted with the source. With a completely active pheromone source, the male moths were attracted to the source in a slow-approach flight and directly contacted the source without step 3. C. binotalis males did not show a mating dance, unlike Chilo suppressalis. ${ }^{9)}$ In Pyraustinae, Dichocrocis punctiferalis ${ }^{11}$ and Glyphodes pyloalis ${ }^{12)}$ have been reported to be without a mating dance for males.

The male attracting activity of the crude extract disappeared when the extract was hydrolyzed. However, the activity was regenerated after the hydrolyzate was acetylated. Hence, the pheromone of $C$. binotalis was presumed to contain acetates.

To evaluate the carbon number of the acetates, the crude extract ( $c a .100$ female equivalents) was fractionated with GC on non-polar OV-101. Standard Z-7-DDA, Z-9-TDA, Z-11HDA and Z-13-ODA were used as markers, and the fractions around the standard compounds were collected as fr. I, II, III and V, respectively (Fig. 1). Each fraction showed no attracting activity. However, combined fractions containing both fr. II and III showed activity. This fact was supported by an EAG activity test; i.e., a mixture of fr. II and III had the highest EAG response. Therefore, the pheromone was presumed to be constituted by at least two components, which might have been acetates of carbon number 14 and 16 .

When the crude extract was fractionated with a Florisil column, the $5 \%$ ether-hexane 


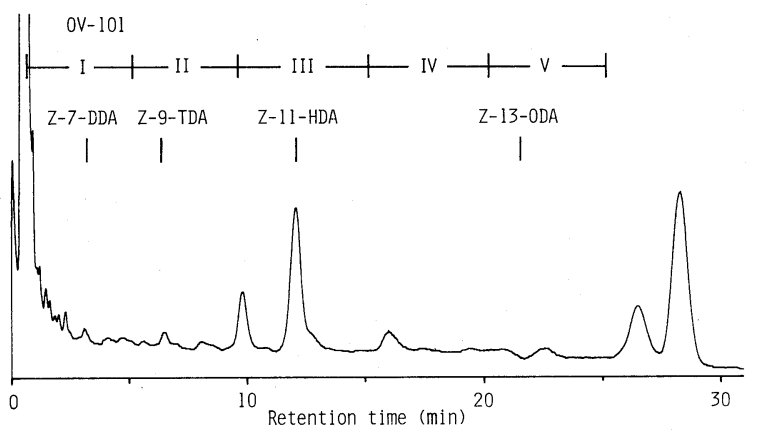

FIG. 1. GC Trace of a Crude Extract of Ovipositor Tips of $C$. binotalis with a Packed OV-101 Column. $\mathrm{I} \sim \mathrm{V}$, fractions collected. The bars show $t_{R}$ of the standard compounds of Z-7-DDA, Z-9-TDA, Z-11-HDA and Z-13-ODA.

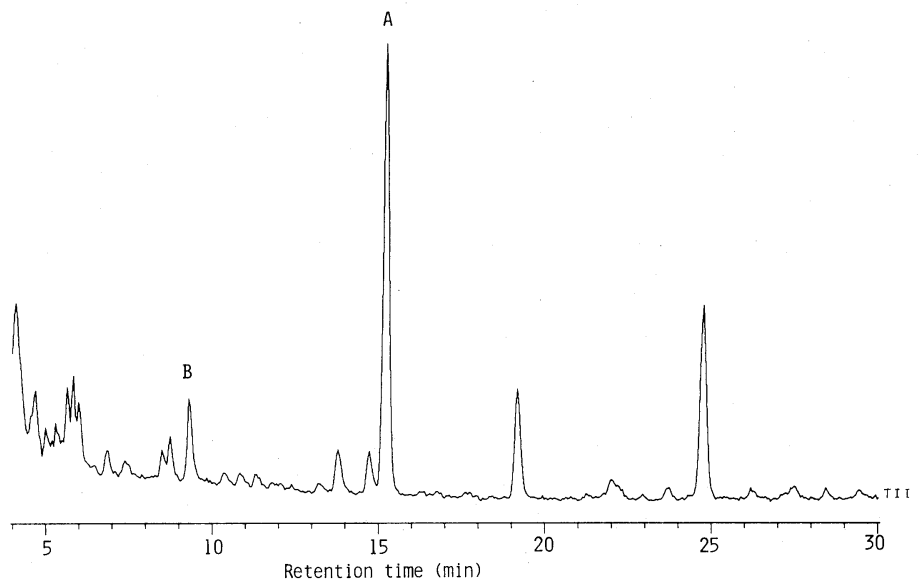

Fig. 2. Total Ion Chromatogram of the $5 \%$ Ether-Hexane Fraction of a Crude Extract on a Florisil Column.

GC/MS with a fused silica capillary column of chemically bonded PEG-20M was used.
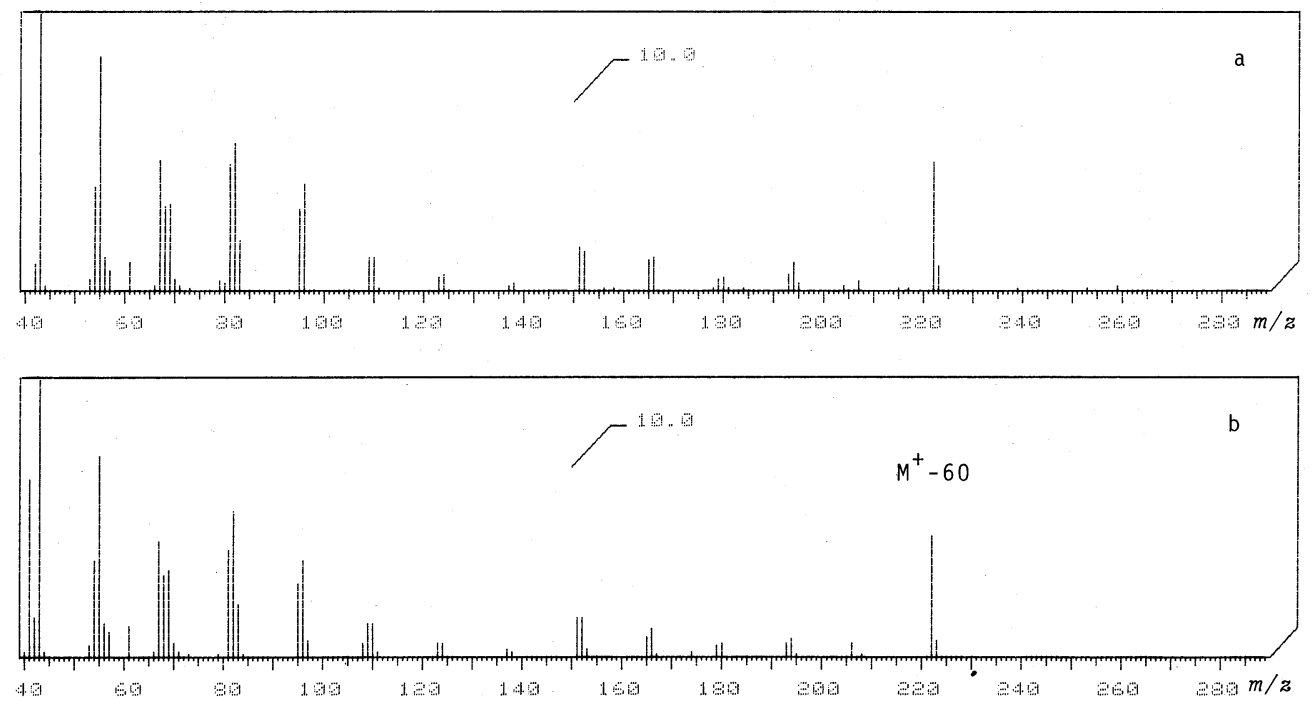

FIG. 3. Mass Spectra of Peak A (Upper) and Standard Z-11-HDA (Lower) by GC/MS. 


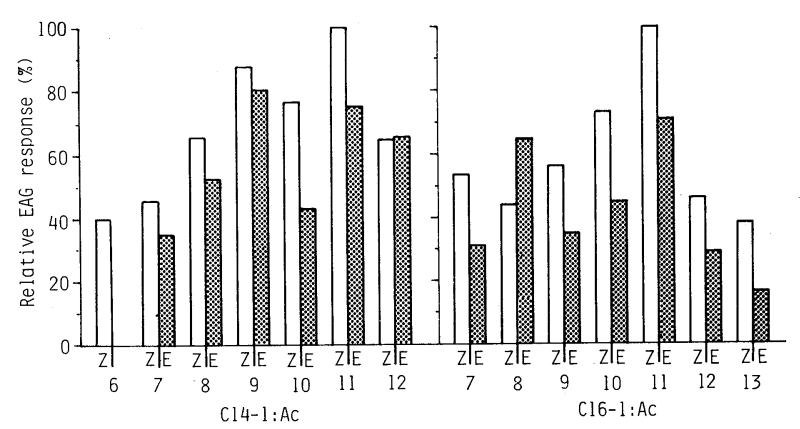

Fig. 4. EAG Responses of Male C. binotalis to Serial Monoene Acetates of Different Double-bond Position and Geometrical Configuration $(n=4)$.

C14-1: Ac, tetradecenyl acetate. C16-1: Ac, hexadecenyl acetate.

fraction had strong male attracting activity. The ether-hexane fraction ( $c a$. 400FE) was analyzed with GC/MS interfaced with a capillary PEG-20M column (Fig. 2). The mass spectrum of the main peak $\mathrm{A}\left(t_{R}, 15.3 \mathrm{~min}\right)$ was coincident with that of standard Z-11-HDA having an $m / z$ of $222\left(\mathrm{M}^{+}-60\right)$ (Fig. 3), and not with E-11-HDA $\left(t_{R}, 15.1 \mathrm{~min}\right)$. The other peaks did not show clear mass spectra because of their insufficient quantity. However, the $t_{R}$ of peak B $(9.4 \mathrm{~min})$ was identical with that of standard Z-9-TDA, and that of Z-11-TDA was $9.8 \mathrm{~min}$. The approximate area ratio of peak A to peak B was $10: 1$.

To deduce the double-bond positions and geometrical configurations of the active components, EAG profiles of serial monoene acetates of $\mathrm{C} 14$ and $\mathrm{C} 16$ were recorded. Z-9-TDA and Z-11-TDA had potent EAG responses in C14 monoene acetates (10 $\mu \mathrm{g}$ each), and Z-11HDA in C16 acetates ( $1 \mu \mathrm{g}$ ) (Fig. 4).

The attractivity of the components to the male moths was confirmed in the wind tunnel using EAG-active synthetic compounds (Table I). A single compound of Z-9-TDA, Z-11TDA, or Z-11-HDA did not show activity. A mixture of Z-9-TDA and Z-11-HDA showed strong activity, and males were attracted to contact the pheromone source in the same manner as that with the crude extract. The addition of Z-11-TDA to the mixture of Z-9TDA and Z-11-HDA did not affect the activity. The activity was found in mixing ratios of the two compounds (Z-9-TDA : Z-11-HDA)
Table I. Attractivity of Synthetic Compounds to $C$. binotalis Males in a Wind Tunnel

\begin{tabular}{cccc}
\hline \multicolumn{3}{c}{ Compound (ng/filter paper) } & \\
\cline { 1 - 3 } Z-11-HDA & Z-9-TDA & Z-11-TDA & \\
\cline { 1 - 2 } 20 & 0 & 0 & - \\
0 & 1,10 & 0 & - \\
0 & 0 & 1,10 & - \\
0 & 1,10 & 1,10 & - \\
20 & 1 & 0 & ++ \\
20 & 0 & 1 & - \\
20 & 1 & 1 & ++ \\
45 & 3 & 0 & + \\
2.5 & 0.1 & 0 & \pm \\
1.0 & 0.04 & 0 & + \\
\hline
\end{tabular}

a See the text.

between $1: 7$ to $1: 60$, and in total amounts between $1 \mathrm{ng}$ and $50 \mathrm{ng}$ on the filter paper strip. The pheromone of $C$. binotalis was established to be about a $1: 10$ mixture of Z-9-TDA and Z-11-HDA, which was, therefore, a reasonable mixing ratio for sufficient pheromone activity.

Many lepidopterous insects utilize straightchain aliphatic acetates as female sex pheromone components. ${ }^{13)}$ Z-11-HDA, Z-9-TDA and Z-11-TDA are the most important components of their pheromones. Z-11-HDA is the major component of Plutella xylostella, ${ }^{3}$ Naranga aenesens, ${ }^{14)}$ Sesamia inferens, ${ }^{15}$ ) Leucania separata, ${ }^{16)}$ etc. In Noctuidae, Z-11HDA and/or Z-9-TDA are major components of the sex pheromone. Eight species of Hadanidae all utilize Z-11-HDA as the phero- 
monal component. ${ }^{13)} \mathrm{Z}-9-$ TDA as well as Z11-HDA is utilized as the major component of most of the subfamily Tortrisinae.

Especially, Mamestra configurata, one of the major pests of rapeseed in Canada, has Z-11HDA and Z-9-TDA as the female sex pheromone components, and the ratio of the two compounds $(19: 1)^{17,18)}$ is very similar to that of $C$. binotalis. Leucania loreyi also utilizes Z11-HDA and Z-9-TDA as the pheromone components, but the ratio is $1: 4$ (Z-9-TDA is the major). ${ }^{16)}$

The amount of Z-11-HDA in an abdominal tip extract of $C$. binotalis (ca. $0.5 \mathrm{ng} / \mathrm{FE}$ ) seemed to be very small at about ten times less than that of $M$. configurata (ca. $5 \mathrm{ng}$ / $\mathrm{FE}){ }^{18)}$ and therefore, $C$. binotalis might respond to only a low concentration of the pheromone, or vice versa.

In $M$. configurata, the addition of Z-7DDA, which exists as $1 \%$ of the total components in the abdominal tip extract, to a blend of Z-9-TDA and Z-11-HDA increased the catches of males in a field test. ${ }^{18)}$ The same phenomenon has also been observed in $L$. loreyi. ${ }^{19)}$ This compound may be a minor component in the $C$. binotalis pheromone, such minor sex pheromone components, including Z-7-DDA, remaining to be examined in the near future. Field tests of attractivity should be also carried out to confirm the components of the $C$. binotalis pheromone, and for application to pest control.

A study on the mating behavior of $C$. binotalis will be reported elsewhere.

Acknowledgments. We are grateful to Mr. Faidil Sjoeib of PAIR-BATAN, Indonesia for his assistance, and to Dr. Koshi Arai of Tokyo University (present address: Sapporo Breweries, Ltd.) and Dr. Hajime Sugie of the National Institute of Agro-Environmental Sciences for their GC/MS analyses and valuable suggestions. We also thank Dr. Tetsu Ando of Tokyo University of Agriculture and Technology, and Shin-etsu Chemical Industries Co., Ltd. for their generous gifts of synthetic compounds.

\section{REFERENCES}

1) R. S. Berger, Ann. Ent. Soc. Am., 59, 767 (1966); L. B. Bjostad, L. K. Gaston, L. L. Noble, H. H. Moyer and H. H. Shorey, J. Chem. Ecol., 6, 727 (1980).

2) Y. Tamaki, H. Noguchi and T. Yushima, Appl. Ent. Zool., 8, 200 (1973).

3) Y. Tamaki, K. Kawasaki, H. Yamada, T. Koshihara, N. Osaki, T. Ando, S. Yoshida and H. Kaminohara, Appl. Ent. Zool., 12, 208 (1977).

4) Y. Hirai, H. Kimura, K. Kawasaki and Y. Tamaki, Appl. Ent. Zool., 13, 136 (1978).

5) S. Wakamura, Appl. Ent. Zool., 13, 290 (1978).

6) A. S. Hill, R. W. Rings, S. R. Swier and W. L. Roelofs, J. Chem. Ecol., 5, 439 (1979).

7) K. Arai, T. Ando, A. Sakurai, H. Yamada, T. Koshihara and N. Takahashi, Agric. Biol. Chem., 46, 2395 (1982).

8) M. Kurihara, S. Tatsuki and J. Fukami, Appl. Ent. Zool., 22 (1987), in press.

9) S. Tatsuki, M. Kurihara, K. Usui, Y. Ohguchi, K. Uchiumi and J. Fukami, Appl. Ent. Zool., 18, 443 (1983).

10) T. Ando, K. Kishino, S. Tatsuki and N. Takahashi, Agric. Biol. Chem., 44, 765 (1980).

11) Y. Konno, H. Honda and Y. Matsumoto, Appl. Ent. Zool., 15, 321 (1980).

12) K. Y. Seol, H. Honda and Y. Matsumoto, Appl. Ent. Zool., 21, 228 (1986).

13) Y. Tamaki, "Comprehensive Insect Physiology, Biochemistry and Pharmacology," Vol. 9, ed. by G. A. Kerkut and L. I. Gilbert, Pergamon Press, Oxford, UK, 1985, pp. 145 191 .

14) T. Ando, K. Kishino, S. Tatsuki, M. Nakajima, S. Yoshida and N. Takahashi, Agric. Biol. Chem., 41, 1819 (1977).

15) B. F. Nesbitt, P. S. Beevor, D. R. Hall, R. Lester and V. A. Dyck, Insect Biochem., 6, 105 (1976).

16) S. Takahashi, M. Kawaradani, Y. Sato and M. Sakai, Jpn. J. Appl. Ent. Zool., 23, 78 (1976).

17) M. D. Chisholm, W. F. Steck, A. P. Arthur and E. W. Underhill, Can. Ent., 107, 361 (1975); E. W. Underhill, W. F. Steck and M. D. Chisholm, ibid., 109, 1335 (1977).

18) D. L. Struble, G. L. Ayre and J. R. Byers, Can. Ent., 116, 103 (1984).

19) Y. Sato, S. Takahashi, M. Sakai and T. Kodama, Appl. Ent. Zool., 15, 334 (1980); S. Takahashi, Y. Sato, M. Kawaradani and M. Sakai, ibid., 15, 499 (1980). 